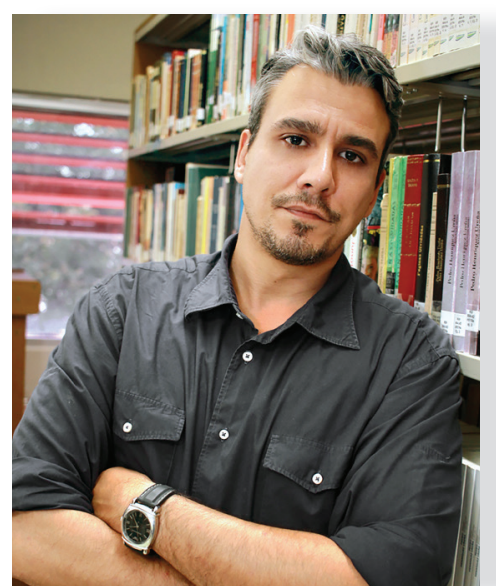

Joan Enric Campà Molist"

\section{La maestría socrática y la democratización ciudadana; un posible remedio a la desorientación de la Academia actual}

\author{
"Socratic Mastery and citizen democratization; a possible \\ remedy to the disorientation of the current academy"
}

Recibido: $12-05-18$

Aprobado: 25-06-18

\title{
Resumen
}

El trance vivido por Sócrates, causado por las acusaciones que lo sentenciaron a muerte, es un buen ejemplo a considerar cuando, aguzando la pupila, pretendemos investigar las influencias del tradicionalismo en la esfera académica y cultural, pues expresa la grave vulneración que sufre la libertad de pensamiento y de expresión a partir del supuesto de infalibilidad arraigado en el folclore. Entendiendo dichas libertades como ejes vertebradores de todo Estado democrático, percibidas a la vez como una construcción erigida desde la Academia, la presente analogía puede servir para esclarecer el desequilibrio sociocultural de tantos Estados considerados como democráticos. En este sentido, mediante una investigación cualitativa fundamentada en la documentación bibliográfica y la reflexión, se plasmará cómo y porqué la Academia en general, cual funambulista, transita inoculada por influencias socioculturales y políticas perniciosas; los óbices que propician una ceguera intelectual y moral en el ámbito social.

\section{Abstract}

The trance experienced by Socrates, concerning his sentence to death, is a good example to consider when, straining the pupil, we intend to investigate the influences of traditionalism in the academic and cultural sphere, because it expresses the serious infringement that suffers the freedom of thought and expression from the assumption of infallibility rooted in folklore. Understanding these freedoms as backbone axes of every democratic state, perceived at the same time as a construction erected from the academy, the present analogy can serve to clarify the present democratic imbalance in so many states considered democratic. In this sense, through a qualitative investigation based on the bibliographical documentation and the reflection, it will analyse how and why the Academy in general, which tightrope Walker, travels inoculated by sociocultural influences and pernicious policies; the obstacles that lead to an intellectual and moral blindness in the social sphere.

\section{Palabras clave}

Maestría socrática; supuesto de infalibilidad; libertad de pensamiento y de expresión; desarrollo intelectual; Academia actual

\section{Keywords}

Socratic mastery; assumption of infallibility; freedom of thought and expression; intellectual development; actual Academy

*Joan Enric Campà Molist: Graduado en Filosofía por la Universitat Autònoma de Barcelona (UAB). Magister en Derechos Humanos, Democracia y Globalización por la Universitat Oberta de Catalunya (UOC). Doctorando en Filosofía Política y Derechos Humanos, en la Universitat Autònoma de Barcelona (UAB). Profesor a Tiempo Completo del Departamento de Humanidades y Director del Departamento de Estudios Generales de la Pontificia Universidad Católica Madre y Maestra - Campus Santo Tomás de Aquino (PUCMM-CSTA) Santo Domingo - República Dominicana. Para contactar al autor:joancampa@pucmm.edu.do 


\section{Introducción}

Si bien el pensamiento de la Antigua Grecia ${ }^{1}$ ha sido durante la historia del ser humano un ejemplo referencial y de digna admiración, especialmente desde el ámbito filosófico, literario, político, artístico, tecnológico y científico, debe constatarse, sin embargo, que muchos de los valores morales con los que se configuraba sociopolíticamente serían, a ojos de nuestra contemporaneidad, repulsivamente inconcebibles y rechazados. Tendemos a interpretar el legado griego como una panacea para los dolores del mundo contemporáneo, y lo es en un amplio sentido, pues el firmamento filosófico que iluminó las distintas épocas de la Hélade brindó un importante aporte a la historia del conocimiento, pero el modo de estratificar la ciudadanía, concebir y vivir aspectos de la vida humana tan cotidianos como la muerte, la sexualidad, la libertad-esclavitud y la condición de ser hombre-ser mujer, por mencionar algún ejemplo, era tan distinto como moralmente opuesto a nuestro entender.

No obstante a tan alto grado de disimilitud moral, sí podemos afirmar que existieron necesidades socioculturales y políticas idénticas a las que se requieren en tantas sociedades actuales, especialmente las propias de la Época Clásica de Grecia y la Academia actual, a saber: 1) de hacer florecer una auténtica democracia 2 ; 2) de "desafiar" a la autoridad del tradicionalismo, en aras de la verdad, la justicia y el desarrollo, mediante el análisis lógico y la argumentación crítica de la ciudadanía; 3) de ampliar el margen de acción de la libertad de pensamiento, de expresión y de libre desarrollo del ciudadano, y 4) de permitir que la razón se adueñe del núcleo sociocultural y político desde el escenario educativo democratizado y democratizador. Cuatro necesidades que, como conditio sine qua non, deben solventarse desde la esfera de la educación por ser esta el sustrato del cultivo cultural, intelectual y moral de una sociedad. Por ende, no solamente es interesante realizar una analogía entre ambas etapas históricas para cotejar sus marcos educativos, culturales y políticos, sino, más importantemente, para plantear nuevas veredas y soluciones aplicables a la actual "realidad" académica.

Sócrates, filósofo perteneciente a la Atenas de la Época Clásica y considerado como el eje central de la civilización occidental, del mismo modo que Jesús de
Nazaret (Steiner, 2003), merece un espacio con el cual abordar la esfera de la educación actual por "obligarnos a ponderar la íntima relación entre la filosofía, la pedagogía, la ética y la política" (Álvarez, 1994, p. 5). Debemos recordar el legado pedagógico de Sócrates por haber batallado contra las distintas formas de poder adueñadas del ámbito político y cultural ateniense, tales como la inamovible tradición homérica, la nociva falta de coherencia y veracidad del discurso político y la sacralización de los contenidos educativos, las cuales provocaron una significante ceguera intelectual y moral de una amplia parcela de la pólis (ciudad-Estado).

En este orden de ideas, las líneas que siguen plasmarán aspectos análogos que podrían contribuir al fortalecimiento educativo de la Academia en general y los modos de entender la naturaleza de la educación. Inicialmente, nos encontraremos con las características que erigieron la educación griega o paideia, especialmente desde la literatura de Homero y Hesíodo (Apartado 1). Seguidamente, desde el pensamiento, vida y maestría de Sócrates, comprenderemos la postura del "maestro-discípulo" en un entorno sociopolítico complejo (Apartado 2), y analizaremos "nuevas" metodologías de enseñanza como la mayéutica o la enseñanza dialógica (Apartado 3). Al mismo tiempo, se abordarán los nexos entre el poder político, cultural y religioso de una sociedad y la esfera educativa, como el supuesto de infalibilidad del tradicionalismo, el papel de la democracia y la libertad de pensamiento y expresión, y determinados dogmas extendidos como "intoxicaciones que castran el desarrollo intelectual" y que, como añadido, contribuyen a generar ideologías obsoletas y discriminatorias de talante fascista (Apartado 4). Sin alejarnos de la órbita que nos concierne y con un enfoque más optimista, el presente texto plasmará ciertos atributos académicospedagógicos que podrían contribuir a la florescencia de una educación democratizadora, como son, en calidad de propuesta, los atributos que describen la naturaleza del concepto de "Estudios Generales" (Apartado 5); un concepto educativo que bien puede ser entendido como salvífico pero que, generalmente, permanece en la inopia más abrupta de tantas parcelas de la Academia.

La finalidad del presente paper se reduce, por una parte, a alumbrar ciertos aspectos fantasmagóricos que irrumpen cáusticamente en un ámbito tan indispensable como el de la educación y la enseñanza, $y$, por otra parte, a presentar determinadas soluciones que democraticen la labor de la Academia; el medio

\footnotetext{
1. Desde el neolítico griego (6.500-3.000 a.C.), la Edad del Bronce (3.000-1.150 a.C.) y la Edad Oscura (1.150-750 a.C.) hasta la Época Arcaica (750-490 a.C.), la Época Clásica (490-323 a.C.) y el Helenismo (323-30 a.C.).

2 A pesar de ser considerada la Grecia Clásica como la cuna de la democracia, ofreciendo al pueblo (démos) el poder de gobernar (krátos) elevando la importancia del voto igualitario e igualdad ante la ley (isonomia), la libertad de expresión o derecho a ser escuchado (isegoria) y el libre acceso a las funciones públicas (isotimia), la libertad de pensamiento es un atributo que se distancia de lo permisible sociocultural y políticamente.
} 
desde el cual todos los docentes que amamos tan digna profesión, entendiéndola como una catapulta que impulsa a la sociedad hacia el desarrollo, procuramos respetar y cuidar para originar, reanimar o fortalecer los sentidos más humanizadores de nuestros estudiantesconciudadanos.

\section{La educación griega, o paideia, y la omnipotencia de la literatura homérica.}

Tal como inmortaliza la pluma de Platón, se describe a Homero como el distinguido ${ }^{3}$ "educador de la Hélade" (Platón, 2013, 606 e), en la medida en que la difusión de los pensamientos homéricos y los contenidos mitológicos ${ }^{4}$ era la privilegiada labor de los poetas y rapsodas; los cuales contaban con la validez pedagógica de sus obras literarias por aunar las fuerzas estéticas y éticas del ser humano (Jaeger, 1996). En este sentido, la educación griega se basaba en los héroes homéricos y la espontánea vitalidad y libertad que estos derrochaban en sus hazañas, en unas actitudes y valores ${ }^{5}$ concebidos como un ideal de conducta que, con un carácter normativo, no cesaron de permear en la sociedad mediante la paideia (del griego maıठદía), o educación ${ }^{6}$.

En esencia, la paideia consistía en la transmisión de valores y saberes que, a partir del modelo homérico, tenían como fin la formación cultural de individuos cívicos ${ }^{7}$ : individuos que aspirarían a un ideal de hombre marcado por una virtud-excelencia, o areté (del griego ápeтń), de talante mitológico. Un ejemplo pedagógico desentrañado del ideal homérico se expone en la obra magna de Homero, La Odisea, cuando Odiseo debe superar las tentaciones carnales y espirituales despertadas por los cánticos y belleza de las sirenas:

Oye ahora lo que voy a deciry un dios en persona te lo recordará más tarde. Llegarás primero a las sirenas, que encantan a cuantos hombres van a su encuentro. Aquel que imprudentemente se acerca a ellas y oye su voz, ya no vuelve a ver a su esposa ni a sus hijos pequeñuelos rodeándole, llenos de júbilo, cuando torna a sus hogares; sino que le hechizan las sirenas con el sonoro canto, sentadas en una pradera y teniendo a su alrededor enorme montón de huesos de hombres putrefactos cuya piel se va consumiendo. Pasa de largo y tapa las orejas de tus compañeros con cera blanda, previamente adelgazada, a fin de que ninguno las oiga; mas si tú desearas oírlas, haz que te aten en la velera embarcación de pies y manos, derecho y arrimado a la parte inferior del mástil, y que las sogas se liguen al mismo; y así podrás deleitarte escuchando a las sirenas. $Y$ caso de que supliques o mandes a los compañeros que te suelten, átente con más lazos todavía (Homero, 2016, Canto XII, vv. 31 y ss.).

Tal como puede inferirse, se expone un ideal de hombre muy marcado y acotado que ejemplifica un gran espíritu de aventura y heroicidad, una templanza y una serenidad que, en virtud de la fidelidad a la familia y del amor a la vida, deben prevalecer sobre los deseos carnales que aviva la belleza estética. Por lo que se desprende, La Odisea no debe ser entendida, exclusivamente, como una obra literaria sino también como un manual ético para el hombre griego (Marrou, 2004). No obstante a la finalidad formativa de tal obra, cabe abordar una característica significativa de la misma: los valores transmitidos eran incuestionables e irremplazables, insustituibles e inalienables, pues dudar tanto de su veracidad como de su infalibilidad era un insulto a los dioses y una ofensa a la cultura establecida.

Resulta extremadamente difícil categorizar un "sistema educativo" como el descrito como un sistema puramente democrático ${ }^{8}$, pues formar ciudadanos democráticos, stricto sensu, significa formar a ciudadanos con la capacidad de pensar por sí mismos desde la libertad y la creatividad, permitir el igual acceso a la educación de todos los ciudadanos sin distinción alguna, propiciar una autonomía intelectual mediante el análisis lógico

\footnotetext{
${ }^{3}$ Empero, el poeta Hesíodo también permeó, aunque no tan significativamente como Homero, en la cultura y la tradición griega mediante su literatura mitológica, como la obra Teogonía, con la cual relata la genealogía de la familia divina.

${ }^{4}$ Desde la óptica etimológica, el término "mito" proviene de mythos (del griego $\mu u ̃ \theta o c$, cuyo significado originario se atribuía, con una amplia ambigüedad, a "palabra, relato, narración, fábula o cuento". Ya en la época ilustrada de la Atenas del s. V a.C., la palabra mythos pasó a designar el relato tradicional; lo opuesto al discurso razonado o lôgos.

${ }^{5}$ Como el amor a la gloria, al honor, a la valentía y a la caballerosidad.

${ }^{6}$ La cual agrupaba nociones sobre filosofía, retórica, matemáticas, poesía y gimnasia: los conocimientos considerados suficientes para que el individuo tuviera un cuidado de sí mismo.

${ }^{7}$ No obstante, recordando el carácter estratificado de la antigua Grecia, la educación quedaba reservada para los hombres libres (excluyendo a las mujeres, a los esclavos y a los extranjeros (metecos), considerados estos parte de una categoría alejada a la de "ciudadano"), los cuales debían ser capaces de mandar y hacerse obedecer mediante una paideia de carácter cívico-integral de carácter homérico, el germen de las humanidades (humanitas).

${ }^{8} \mathrm{Tal}$ como entendemos hoy día la democracia, sustentada esta por los principios de libertad, igualdad y autonomía de los ciudadanos.
} 
y el dominio de la argumentación crítica, fortalecer la templanza emocional (la cual identifica y controla los sentimientos y emociones mediante el autoconocimiento) y auspiciar un equilibrio espiritual ${ }^{9}$ como resultante. Se $^{-}$ trata pues, de unos aspectos que la educación griega no consideraba parte de la teoría democrática, pues los maestros griegos no tenían una noción democrática del aprendizaje como la que podemos entender hoy día: la verdad no era considerada "accesible a todos los ciudadanos" (Nussbaum, 2005, p. 41). A pesar de tales diferencias, el mundo griego fue notoriamente rico por el florecimiento de tendencias pedagógicas contraventoras que retaban a lo establecido, a saber: 1) la educación propuesta por Pitágoras, la cual se fundamentaba en la armonización de la vida humana con el universo desde las matemáticas 2) la educación propuesta por Isócrates, la cual se centraba en el lenguaje y la retórica 3 ) la educación propuesta por Jenofonte, la cual puede considerarse la primera que integraba a la mujer en el ámbito educativo 4) La educación pública que pretendía Platón, la cual, como ejemplo significativo, tenía como fin evitar cualquier pretensión totalitarista desde la esfera política (Gadotti, 2003).

De los filósofos mencionados, empero, fue Pitágoras quien postuló un principio educativo claramente deformador y antihomérico que retaba al vigor de lo establecido por la tradición homérica, especialmente por su preocupación por el cultivo de la autonomía de pensamiento. Fue este quien prescribía a sus discípulos la obligatoriedad de realizar un examen de conciencia al finalizar el día: un aspecto contrario a los pilares del conservadurismo homérico y el ideal pedagógico establecido, pues el examen de conciencia contribuye directamente al cuestionamiento de lo establecido y a su posible desmoronamiento. También, y posterior a Sócrates y Aristóteles, Epicuro de Samos ideó una dieta alimenticia para los atletas que contradecía los estándares religiosos ${ }^{10}$; un modo de desafiar la irracionalidad de lo normativamente establecido mediante el estatismo del tradicionalismo homérico.

Aristófanes, contrariamente a los casos anteriores, fue el más genuino representante del conservadurismo ateniense, pues, a pesar de su burla hacia los dioses, "enfocaba con respetuosa seriedad la fuerza de la tradición" (Tovar, 1986, p. 58). Sostuvo que la educación de los jóvenes atenienses se basaba, y debía perseverar, en la asimilación forzosa de los valores tradicionales (Nussbaum, 2005); el alumnado aprendía de un modo imperativo y hermético aquello que el tradicionalismo homérico y la autoridad permitían saber. En este orden de ideas, se internalizaba la cultura desde la suprema obligación sin margen ni opción a la cuestión o contradicción; tal modelo pedagógico empalizaba al conocimiento en virtud de lo que debía saberse y lo que no debía saberse.

En un escenario educacional con unos sesgos tan tradicionalistas, impermeables y obtusos como el homérico, hubo una personalidad que, desafiando a lo establecido dogmáticamente, manifestó el carácter más rebelde e indomable de la filosofía. Un ciudadano que originó nuevas veredas de acceso al conocimiento mediante una transgresora forma de manejar el lôgos

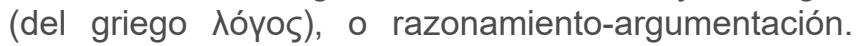
Un ser humano que, por su templanza, conciencia de sí mismo y lealtad por, para y desde la justicia y el Derecho ateniense, ha pasado a considerarse un hecho histórico que todavía late en el pensamiento occidental. Un maestro que por su austeridad y dedicación prensó una importante huella en el espíritu de sus discípulos ${ }^{11}$. Un símbolo del pensamiento que por su legado filosófico puede interpretarse, por un amplio abanico de aspectos, como un ideal de conducta intelectual y moral. Este, es Sócrates.

\section{Sócrates y el fantasma de la democracia; la oposición filósofo-sofista.}

Cuando nos imaginamos a nuestro filósofo, bajo la herencia y tutela documental de Platón, Jenofonte y Aristófanes $^{12}$, debemos imaginarnos la figura del maestro extremadamente austero y dedicado al cultivo del intelecto (tanto al propio como el de sus discípulos e interlocutores-ciudadanos), del vecino comprometido con la democracia ateniense desde la óptica de la razón y del urbanita fervientemente enamorado de la polis que habitaba. Desde el plano pedagógico, debemos imaginarnos al dialogador que, con pulcra genialidad, aguijoneaba cual tábano las inconsistencias argumentativas de sus interlocutores, al anti-maestro

\footnotetext{
${ }^{9}$ Un estado similar a la ataraxia epicúrea, del griego átapałia, la cual define una condición existencial del individuo que, mediante el control de los propios placeres, carece de perturbaciones.

${ }^{10}$ En lugar de basar el régimen en higos secos, cereales y queso fresco, tal como postulaba la vieja tradición religiosa, recomendó una dieta de carne para fortalecer el potencial de los atletas.

${ }^{11}$ Especialmente en Platón y Antístenes. El primero lo demuestra al proyectar a Sócrates como el eje central de la mayoría de su literatura filosófica, y el segundo por las influencias conductuales del maestro, tales como la humildad, la autosuficiencia y la abstinencia.

${ }^{12}$ Considerados estos los pocos que pueden ser testigos directos tanto de su vida personal como de su vida intelectual, pues Sócrates, tal como se destacará en el andar de la presente lectura, no escribió ni dejó ningún testamento filosófico en absoluto.
} 
que rehusaba la concepción de "maestro" (Brun, 2005), al pensador que nunca cesó de considerarse discípulo ante la "fecunda" ignorancia que, irónicamente, siempre se inculcó con su célebre cita "solo sé que no sé nada" (Platón, 2007, 21d).

Sócrates vivía en un entorno muy difícil, en un contexto social democráticamente implicado en los asuntos públicos, pero sin las técnicas adecuadas para deliberar y discernir correctamente ${ }^{13}$; un aspecto que convierte al fenómeno democrático en un estafermo. El análisis lógico, la argumentación crítica, la defensa por el bien común, la verdad y la justicia no eran atributos propios de las decisiones populares, pues la servidumbre al tradicionalismo y al dogmatismo arraigado y erigido desde la educación homérica, auspiciaba una importante ceguera intelectual y moral; el obstáculo principal para la instauración de la razón como instrumento público-político.

Nuestro filósofo, inmerso en una sociedad que se fundamentaba en una enseñanza tan obtusa y atrancada, era considerado el perturbador del pensamiento moral de los jóvenes y el destructor del orden divino establecido; podemos imaginar que nuestro protagonista, ya sea en el ágora, en las escalinatas de los templos, en los mercados o calles atenienses, se enfrentaba solo ante la muchedumbre ciudadana en aras de la razón, la verdad y la justicia. Empero, tal como postula la tinta de Aristófanes, el talante de Sócrates también puede entenderse de un modo muy distinto al descrito por Jenofonte o Platón, pues, en la obra Nubes, nuestro personaje adquiere el papel de bufón y charlatán (Aristófanes, 2012); un protagonismo similar al del sofista más rebuscado e interesado en conseguir la verdad del modo más retóricamente injusto ${ }^{14}$.

Un especial enemigo de nuestro protagonista, y también de la democracia y la razón, fue la sofística o "el arte de convencer y persuadir" de tantos "maestros de cultura" (en sustitución de los anteriores poetas y rapsodas), los cuales contaminaban el ambiente democrático de Atenas con discursos argumentativamente pobres, pero aparentemente irrefutables ${ }^{15}$. Bien podría afirmarse que todo el corpus platonicum (cuerpo literario de Platón) se circunscribe -abordando problemáticas sobre el amor y la belleza (desde El Banquete y Fedro), la virtud o excelencia (desde Menón), el placer y la vida buena (desde Filebo), la justicia y el orden social (desde La República y Las Leyes), especialmente ${ }^{16}$ - en torno a la oposición entre la técnica sofística y la técnica dialógica de Sócrates; entre la postura retórica del sofista y la postura mayéutica del filósofo.

El afán pedagógico de Protágoras, Antifón, Pródico y otros reconocidos sofistas como Gorgias e Hipias, por ejemplo, era convertir la educación en un ideal perfecto mediante la sofística y la retórica, pero se trataba de un ideal estático, inamovible, inapelable y cercado, peligrosamente contrario a las características naturales del desarrollo sociocultural que, per se, se desarrollan en el tiempo y espacio desde la vulnerabilidad, la porosidad, la flexibilidad y la apertura a nuevos horizontes. El conocimiento, desde el punto de vista de un sofista, no era la finalidad de la praxis educativa, sino que la esencia de la pedagogía se reducía, exclusivamente, al saber práctico como medio y a la fama o reconocimiento como fin. En otras palabras, se entendía que el papel del conocimiento no era un fin en sí mismo sino un medio instrumentalizado para conseguir, en apariencia, la razón. En este punto, es interesante exponer cómo Aristóteles concebía la conducta sofista, considerada como "una sabiduría aparente, pero no real, y el sofista es un traficante en sabiduría aparente, pero no real" (Aristóteles, 2001, I. 165).

La primera diferencia entre la postura socrática y la postura sofística en la metodología educativa, prima facie, es la actitud con la que se inicia el diálogo-debate: mientras que la primera se expone desde una humildad intelectual desconcertante, la segunda presenta al mismo sofista como un sabio petulante (Tovar, 1986). La segunda diferencia florece de la intencionalidad del discurso de cada uno de los interlocutores: cuando la brillante dialéctica sofista procura triunfar elevando el razonamiento débil sobre el fuerte, la argumentación socrática resta en la exigencia de la lógica para elevar la verdad por encima de la certeza. La tercera diferencia recae en la técnica con la que se dirigen los argumentos: mientras que el sofista instrumentaliza

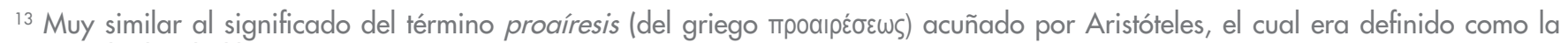
acción de decidir libre y autónomamente.

${ }^{14}$ A pesar de considerar el legado de Aristófanes como "válido", podemos inferir que no tiene el mismo vigor que "el Sócrates" expuesto por Platón o Jenofonte, pues el contacto con el maestro de los dos últimos fue significativamente más directo, constante e intenso.

${ }^{15}$ No obstante, tal como sostiene Jaeger y otros como Guthrie, a los sofistas se les debe atribuir el mérito de ser, estrictamente, los primeros pedagogos de la paideia, aunque con peligrosas pretensiones de enseñar la areté (virtud o excelencia); uno de los motivos por los cuales la decadencia se apoderó de los mismos y de su prestigio.

${ }^{16}$ También en las obras Protágoras y El Sofista, de Platón, se expone el antagonismo filósofo-sofista, una dicotomía que permanece en las inquietudes intelectuales atenienses.
} 
falsedades con el fin de construir una verdad absoluta, Sócrates, mediante la mayéutica, consigue iluminar las contradicciones del "adversario" a partir de las inconsistencias lógicas de sus argumentos. La cuarta diferencia, y última, a saber, es el resultado del diálogo: Sócrates hace retornar a los interlocutores al punto inicial del diálogo para mostrar la invalidez de la hipótesis inicial y, consecutivamente, a la aceptación de la ignorancia del oponente y a la imposibilidad de contradecir al filósofo. Un ejemplo de esta última característica, propia de la cuarta fase del método socrático o mayéutica, es la conclusión a la que llega el joven Eutidemo en un diálogo con Sócrates: "En trance me pone decir que sí también a eso mi estupidez -ya se ve- y mi bastedad; y voy pensando si no me será lo mejor callarme: pues viendo estoy que va a resultar sin más que no sé nada" (Jenofonte, 1967, p. 155).

Sin embargo, una de las diferencias más significativas entre ambos tipos de enseñanza, también en contraste a la profesionalidad docente actual, es que Sócrates no cobraba ni un solo dracma (del griego $\delta \rho \alpha \chi \mu \tilde{)}$ de su maestría, pues era consciente de que los diálogos "pedagógicos" que mantenía con sus interlocutores retroalimentaban tanto al discípulo como a él mismo; tanto uno como otro adquirían conocimiento mediante el contacto dialógico entre discípulo-maestro ${ }^{17}$; una situación que imposibilita asignar un precio. La afirmación que sostiene Kierkegaard cuando califica a Sócrates de "autopático y simpático" (Brun, 2005, p. 51) es coherente, pues no estaba interesado en recibir ningún tipo de gloria, ni recompensa, ni cargos honoríficos; un posible motivo que explica el silencio literario de nuestro filósofo ${ }^{18}$.

En relación a dicha ausencia literaria, cabe mencionar que Sócrates consideraba que los textos escritos propician que los autores corran el riesgo de considerarse sabios (doxosóphoi), pero no sabios de verdad (sophoí); pues, para nuestro filósofo, el diálogo ${ }^{19}$ es el auténtico instrumento para operar el conocimiento en los individuos. Tal como sostiene en Fedro, de Platón, la obra escrita aniquila la fuerza del diálogo entre el autor y el lector: "Pues es esto también lo que me parece terrible de la escritura, Fedro, y que es realmente igual a lo que ocurre con la pintura. De hecho, los seres que la pintura engendra tienen aspecto de estar vivos, pero si les preguntamos alguna cosa, callan, llenos de dignidad. Lo mismo ocurre con los escritos: todos creerían que hablan como si pensaran, pero si se les dirige la palabra con la intención de que aclaren algunas de las cosas que han dicho, entonces sólo expresan una cosa que siempre es la misma." (Platón, 1988, 275d).

\section{La mayéutica y la ironía socrática; el signo distintivo entre la educación dialógica del filósofo y la educación retórica del sofista.}

La mayéutica es el método con el cual, Sócrates, establece una confrontación de argumentos y teorías rivales con la que alumbrar las inconsistencias retóricas del "adversario" (Taylor, 2017, p. 131). El término "mayéutica" con el que nuestro filósofo acuña

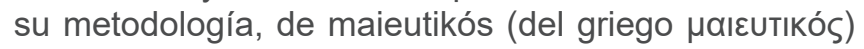
o "el arte de dar a luz", es una muestra de la influencia que este recibió de su madre Fenáreta, partera de profesión. Entendiendo que el conocimiento era considerado el fruto de la reminiscencia o el arte de recordar $^{20}$, la mayéutica era la técnica "pedagógica" para despertar el conocimiento desde el interior del individuo; Sócrates dio un vuelco al sentido clínico del término para asignarle un sentido filosófico: "el arte de parir conocimiento".

Como toda técnica, la mayéutica se desarrollaba mediante ciertas fases o momentos clave que, mediante el cuestionamiento dialéctico, servían para guiar el diálogo y evidenciar, irónicamente, la ignorancia del interlocutor, a saber: 1) el establecimiento de una hipótesis inicial de carácter particular (en la mayoría de los casos, presentada de un modo desafiante por el interlocutor); 2) el cuestionamiento socrático de dicha hipótesis mediante analogías de carácter general; 3) confusión y reconocimiento de la contradicción por parte del interlocutor; 4) demostración socrática de la falsedad de las premisas iniciales; 5) la conclusión verdadera, o aletheia (del griego á $\lambda \hat{\theta} \theta \varepsilon ı \alpha$ ), y aceptación de la ignorancia del interlocutor. Un claro ejemplo del ejercicio mayéutico de Sócrates es el que Platón expone, en el diálogo entre Agatón y Sócrates, en la obra El banquete:

\footnotetext{
17 Una muestra de la conducta tan aversiva que tenía Sócrates ante el término "maestro", considerado por tantos autores como un "anti-maestro" por equipararse al mismo "nivel" que sus discípulos.

18 Otros autores, como A. E. Taylor, sostienen que Sócrates pertenecía al siglo de Pericles, y los hombres de tal época no escribían libros. No obstante, otros teóricos sostienen lo contrario, pues las grandes obras de Esquilo, Sófocles, Píndaro o Eurípides fueron escritas durante el periodo socrático.

19 Para Sócrates, el diálogo con el interlocutor era una brillante oportunidad para conocerse y comprenderse a sí mismo, el primer paso hacia el largo camino hacia la sabiduría.

20 Pues el conocimiento no era considerado como un "ente" exterior sino que, contrariamente, era extraído desde el interior del individuo mediante métodos externos; por lo que el "aprender" no era más que "recordar".
} 
- En verdad, querido Agatón, me pareció que has introducido bien tu discurso cuando decías que había que exponer primero cuál era la naturaleza de Eros mismo y luego sus obras. Este principio me gusta mucho. Ea, pues, ya que a propósito de Eros me explicaste, por lo demás, espléndida y formidablemente, cómo era, dime también lo siguiente: ¿es acaso Eros de tal naturaleza que debe ser amor de algo o de nada? Y no pregunto si es amor de una madre o de un padre — pues sería ridícula la pregunta de si Eros es amor de madre o de padre-, sino como si acerca de la palabra misma "padre» preguntara: ¿es el padre padre de alguien o no? Sin duda me dirías, si quisieras responderme correctamente, que el padre es padre de un hijo o de una hija. ¿O no?

- Claro que sí —dijo Agatón.

- ¿Y no ocurre lo mismo con la palabra «madre»? También en esto estuvo de acuerdo.

- Pues bien -dijo Sócrates- respóndeme todavía un poco más, para que entiendas mejor lo que quiero. Si te preguntara: ¿y qué?, ¿un hermano, en tanto que hermano, es hermano de alguien o no?

Agatón respondió que lo era.

- ¿Y no lo es de un hermano o de una hermana? Agatón asintió.

— Intenta, entonces — prosiguió Sócrates-, decir lo mismo acerca del amor. ¿Es Eros amor de algo o de nada?

- Por supuesto que lo es de algo.

- Pues bien - dijo Sócrates-, guárdate esto en tu mente y acuérdate de qué cosa es el amor. Pero ahora respóndeme sólo a esto: ¿desea Eros aquello de lo que es amor o no?

— Naturalmente - dijo.

- ¿Y desea y ama lo que que desea y ama cuando lo posee, o cuando no lo posee?

- Probablemente —dijo Agatón- cuando no lo posee.

- Considera, pues - continuó Sócrates-, si en lugar de probablemente no es necesario que sea así, esto es, lo que desea desea aquello de lo que está falto y no lo desea si no está falto de ello. A mí, en efecto, me parece extraordinario, Agatón, que necesariamente sea así. ¿Y a ti cómo te parece?

— También a mí me lo parece —dijo Agatón.

- Dices bien. Pues, ¿desearía alguien ser alto, si es alto, o fuerte, si es fuerte?

— Imposible, según lo que hemos acordado.

- Porque, naturalmente, el que ya es no podría estar falto de esas cualidades.

- Tienes razón.

— Ea, pues — prosiguió Sócrates—, recapitulemos los puntos en los que hemos llegado a un acuerdo. ¿No es verdad que Eros es, en primer lugar, amor de algo y, luego, amor de lo que tiene realmente necesidad?

— Sí - dijo.

- Siendo esto así, acuérdate ahora de qué cosas dijiste en tu discurso que era objeto Eros. O, si quieres, yo mismo te las recordaré. Creo, en efecto, que dijiste más o menos así, que entre los dioses se organizaron las actividades por amor de lo bello, pues de lo feo no había amor. ¿No lo dijiste más o menos así?

— Así lo dije, en efecto —afirmó Agatón.

- Y lo dices con toda razón, compañero — dijo Sócrates- Y si esto es así, ¿no es verdad que Eros sería amor de la belleza y no de la fealdad?

Agatón estuvo de acuerdo en esto.

- ¿Pero no se ha acordado que ama aquello de lo que está falto y no posee?

- Sí -dijo.

— Luego Eros no posee belleza y está falto de ella.

- Necesariamente — afirmó.

- ¿Y qué? Lo que está falto de belleza y no la posee en absoluto, ¿dices tú que es bello?

- No, por supuesto.

- ¿Reconoces entonces todavía que Eros es bello, si esto es así?

- Me parece, Sócrates —dijo Agatón-, que no sabía nada de lo que antes dije.

— Y, sin embargo — continuó Sócrates-, hablaste bien, Agatón. Pero respóndeme todavía un poco más. ¿Las cosas buenas no te parecen que son también bellas?

- A mí, al menos, me lo parece.

- Entonces, si Eros está falto de cosas bellas y si las cosas buenas son bellas, estará falto también de cosas buenas.

- Yo, Sócrates -dijo Agatón-, no podría contradecirte. Por consiguiente, que sea así como dices.

— En absoluto replicó Sócrates-: es a la verdad, querido Agatón, a la que no puedes contradecir, ya que a Sócrates no es nada difícil. (Platón, 1988, 199c - 201c).

Tal como se denota, mediante una pulcra maestría manifestada desde el ejercicio mayéutico y obedeciendo a las fases anteriormente descritas, Sócrates no solamente conduce a Agatón hacia la evidencia de la inconsistencia lógica de sus creencias, sino que, más atrevida y significativamente, pone en tela de juicio la naturaleza del dios Eros (del griego "Epws) y el fundamento mitológico relacionado con el amor, la atracción sexual y la sexualidad. Otro aspecto impactante del diálogo expuesto, concretamente al final del mismo, es la postura del "maestro" que no se 
concede protagonismo alguno al obtener la razón y "victoria", pues desde una humildad intelectual insólita remite a la verdad como protagonista de su discurso; aludiéndose a sí mismo como un ser imperfecto. Dicha verdad, sin ser poseída por el propio individuo, es parte del lúcido espíritu interior que guía a la razón de Sócrates, el daimonion que, cual oráculo privado, "empuja a nuestro filósofo a la vida espiritual y le impide la entrada a la vida política" (Steiner, 2003, p. 85); el fundamento de la segunda contrapostura entre nuestro filósofo y la estructura y naturaleza del Olimpo.

Por lo que se desprende, se destacan importantes diferencias entre la conducta socrática, propia de "el filósofo" pesquisidor de verdades, y la conducta del sofista, propia del retórico creador y vendedor de verdades (propia de Agatón, influenciado por la sofística de Gorgias); el análisis lógico y la argumentación crítica acometen elegantemente contra el tradicionalismo homérico y el orden divino caracterizado por un supuesto de infalibilidad. Otro ejemplo de desafío y derrumbe del orden divino se expone en el diálogo entre Parménides y Sócrates, en la obra Menón, cuando el primero, después de "sufrir" el ejercicio mayéutico, confirma y corrobora la palabra del segundo:

- Tal como lo hemos acordado, Sócrates, aquellas Ideas no tienen poder sobre nuestras cosas, ni éstas lo tienen sobre aquellas. Unas y otras sólo están relacionadas consigo mismas.

- Así se acordó, en efecto.

- Por consiguiente, aunque el dios tenga parte en la más perfecta Dominación y la más perfecta Ciencia en sí, jamás podrá ejercer su dominio sobre nosotros, ni su ciencia nos conocerá a nosotros ni a ninguna de nuestras cosas. Así como nosotros no tenemos poder alguno sobre ellos con el poder que hay en nosotros, ni conocemos con nuestra ciencia nada de lo divino, por la misma razón ellos, a pesar de ser los dioses, tampoco tienen dominio sobre nosotros ni conocen los asuntos humanos.

- Pero -dijo Sócrates- ¿no es demasiado sorprendente este argumento, ya que priva al dios de la posibilidad de conocer? (Platón, 2005, 134e)

A pesar del éxito argumentativo ejemplificado en el diálogo entre Sócrates y Agatón, y también desde el reconocimiento de la razón socrática por parte de Parménides ${ }^{21}$, hubo una fuerte aversión hacia la argumentación socrática por parte de la mayoría ciudadana, pues la mayéutica del filósofo iluminaba la ignorancia y simplicidad del hombre y, análogamente, la endeblez y fragilidad de la tan alabada tradicionalidad establecida ${ }^{22}$. Sócrates navegaba por unos turbulentos océanos que podrían causarle un naufragio, hasta que, en el año 399 a.C., así resultó. A partir de las acusaciones de Ánito, Meleto y Licón, los cuales presentaron cargos contra Sócrates por corromper a los jóvenes mediante sus discursos metodológicos y por ser impío, la misma ciudad atentó contra él hasta conseguir su sentencia de muerte ${ }^{23}$. El pensamiento socrático, a partir de ese momento, dejó de considerarse el modo racional de aspirar a la verdad para considerarse una fuente de corrupción intelectual y moral. La acusación a Sócrates se planteó de la siguiente manera: "Sócrates es culpable de corromper a los jóvenes y de no creer en los dioses en los que la ciudad cree, sino en otras nuevas divinidades" (Platón, 2007, 24c). La primera acusación se refiere al carácter desafiante y crítico de las enseñanzas socráticas contra el tradicionalismo arraigado, y la segunda acusación se refiere al resultado de sus enseñanzas y a la existencia del daimonion socrático, considerado como el antagonista de las divinidades griegas.

Sócrates, a sus setenta años de edad y sin vacilar ante la copa de cicuta que lo encaminaría hasta la muerte, se despidió de la vida y de sus discípulos por lealtad ${ }^{24}$ a la ley y Derecho ateniense. Una de las últimas declaraciones que nuestro filósofo dirigió a los jueces, tan digna de ser mencionada en las presentes páginas y ser recordada en nuestra memoria, es: "Pero también vosotros, jueces, habéis de estar esperanzados ante la muerte y tener en mente que sólo hay una cosa cierta: que para el hombre honesto no existe ningún mal, ni en vida, ni una vez que ha muerto" (Platón, 2007, 41d). El crimen aquí cometido, por no abusar de burdos eufemismos, brota cuando el prejuicio de inferencias inválidas se convierte en razón, conllevando a que el análisis lógico y la argumentación crítica sean consideradas las hostiles adversarias de lo que es considerado, ad populum, como lo indiscutiblemente verdadero. En este orden de ideas, el supuesto de infalibilidad y la rigidez dogmática iluminan los

\footnotetext{
${ }^{21}$ Conjuntamente a un sinfín de ejemplos con los que Platón, con una aparente muestra de respeto por su maestro manifestada en sus obras, eleva el discurso socrático sobre la retórica sofista.

22 Acaparando desde lo relativo a la metodología educativa y el discurso político, impregnados de peculiaridades sofistas, hasta los fundamentos con los que se erigían las creencias religiosas; la naturaleza y estructura divina postulada por Homero y Hesíodo.

${ }^{23} \mathrm{El}$ Consejo, compuesto por quinientos ciudadanos, cincuenta por cada una de las divisiones administrativas con las que se estructuraba la polis, votaron a favor de su condena a muerte con 280 votos contra 221.

${ }_{24}$ A pesar de que algunos de sus discípulos tenían preparado un plan para fugar a su maestro, este rehusó la alternativa por fidelidad a la ley y el Derecho ateniense, y más profundamente, a sus principios y "verdades".
} 
fundamentos del despotismo, el totalitarismo y todos aquellos centrismos que excluyen la diversidad y libertad de pensamiento y de expresión, y más importantemente, el rechazo a la verdad y la razón. En este punto, resulta oportuno parafrasear a Francisco de Quevedo con una de sus célebres citas: "donde hay poca justicia es un peligro tener razón".

\section{La tiranía del supuesto de infalibilidad; el funambulismo de la democracia y el desarrollo intelectual.}

El supuesto de infalibilidad afirma la imposibilidad de estar en el terreno del error, impidiendo recibir cuestionamientos para así evitar probables refutaciones $\mathrm{y}$, consecutivamente, evitar un posible decaimiento, cambio o elevación sociocultural. Entendiendo que las personas son de naturaleza vulnerable, permeable y flexible respecto al entorno sociocultural del que participan, comportando que las mismas cambien y se desarrollen en el tiempo y espacio desde un gerundio que no permite una determinación identitaria, la tradicionalidad dogmatizada mediante el supuesto de infalibilidad representa el obstáculo para el libre desarrollo de la persona y la sociedad.

Un conflicto que merece ser expuesto en virtud de lo mencionado, sin desalinearnos del contexto griego, es el impulso del conocimiento científico desbancado por el autoritarismo de los dioses griegos, pues, Prometeo, tras haber prometido el bienestar de la humanidad con la aplicación de las ciencias, es amenazado por Zeus con el mensaje "sálvate como puedas" (Farrington, 1973, p. 71).

El supuesto de infalibilidad aquí plasmado debe entenderse como la acotación de lo permisible desde el plano de la obligatoriedad rígida, como la negación de lo posiblemente conocible y mejorado (en este caso, desde las ciencias naturales) mediante la más déspota de las conductas.

De este modo, el supuesto de infalibilidad de lo establecido priva, desde la rigidez más acomodadora, la posibilidad de que florezcan nuevos modos de entender la existencia mediante la reflexión y, con ello, conocer nuevas modalidades de interrelación humanaintelectual-moral, ya sea desde el ámbito político, cultural y científico ${ }^{25}$, especialmente. En este sentido, la libertad de pensamiento y la libertad de expresión, dos de los pilares fundamentales del desarrollo en una democracia (y en términos generales, de la humanidad), son, por antonomasia, dos libertades que sufren una importante obstrucción; la reflexión, la investigación y el desarrollo restan apartados y menospreciados en la más oscura de las sombras.

Otro ejemplo histórico que manifiesta claramente un alto grado del supuesto de infalibilidad, alejados ahora del contexto griego, fue la quema y destrucción de la biblioteca de Alejandría en el año 640 d. C., el principal centro de investigación de la época clásica. Después de sufrir una serie de ataques relativamente fallidos ${ }^{26}$, el General 'Amr ibn al-'Āș invade la ciudad de Alejandría y, por mandato del Califa Umar ibn al-Jattāb, ordena incendiar el edificio y destruir toda la cultura escrita que contenía. El argumento que el Califa sostuvo a la hora de mostrar la infalibilidad del pensamiento musulmán fue: "Si los libros de la biblioteca contienen la misma palabra que el Corán, no existe sentido alguno para conservarlos, pues se repiten. Si los libros contradicen la palabra del Corán, tampoco tiene sentido conservarlos, pues mienten" (Wolff, 2012, p. 135). Más de 700.000 papiros repletos de pensamiento ardieron durante seis meses y sirvieron para iluminar la sombría presencia de un islam indubitable.

Tal como puede inferirse, el supuesto de infalibilidad del Califa Umar ibn al-Jattāb no permitía la existencia de expresiones culturales distintas a la propia, y se pretendió, pues, elevar y perpetuar unas creencias en particular, las cuales eran entendidas como las únicas verdaderas, menospreciando y aniquilando las de otros colectivos humanos en general. En este punto, es conveniente exponer la respuesta de John Stuart Mill a tan alto grado de violación de la libertad de expresión: "existe una notoria diferencia entre presumir que una opinión es verdadera porque oportunamente no ha sido refutada, y suponer que es verdadera a fin de no permitir su refutación" (Stuart Mill, 2013, p. 36). Entendiendo que el único modo de palpar la verdad es permitir que las creencias sean susceptibles al cuestionamiento y a una posible refutación en pro de la Verdad, es necesaria una conducta que puede considerarse en peligro de extinción, un modo de entender la existencia que permite elevarnos hacia el conocimiento desde la tolerancia; la humildad intelectual ${ }^{27}$.

\footnotetext{
${ }^{25}$ Otro importante ejemplo histórico del supuesto de infalibilidad de lo establecido es el caso de Copérnico, y posteriormente Galileo Galilei, los cuales demostraron científicamente el sistema heliocéntrico del sistema solar que contradecía y cuestionaban el sistema geocéntrico de Ptolomeo y los pilares de la Iglesia Católica. Tanto uno como otro tuvieron que enfrentarse muy peligrosamente al supuesto de infalibilidad de lo establecido por el catolicismo, principalmente, entre el sistema deductivo y el sistema inductivo; un enfrentamiento que resaltaba la división entre la teología y la ciencia.

${ }_{26}$ Uno de ellos causado por Julio Cesar el día 9 de noviembre del año 48 a.C.

27 Un atributo que bien puede imputarse, inequívocamente, a la conducta y personalidad de nuestro protagonista, Sócrates.
} 
Un ejemplo más próximo a nuestra etapa histórica que también manifiesta una expansión del supuesto de infalibilidad, el cual brotó en la Europa de entreguerras, es el fascismo ${ }^{28}$. El término "fascismo" acuñado por el conocido dictador italiano, Benito Mussolini, nació para exaltar los valores de la patria y de la raza en el ámbito sociocultural, étnico, político y económico. En este sentido, los rasgos fascistas son los encargados de maquillar el supuesto de infalibilidad de una política, sociedad o cultura en concreto que ubica a una entidad por encima de otra de un modo jerárquico.

El filósofo italiano Umberto Eco (1995) sostiene que existen una serie de indicadores con los que detectar rápidamente los rasgos fascistas de una identidad en concreto e inferir el supuesto de infalibilidad en ella camuflado, estos son: 1) el culto ciego a la tradición y a la alienación ideológica; 2) la abstención y renuncia del pensamiento crítico, el cual auspicia distinciones de pensamiento que son entendidos como indicios de peligro; 3 ) el rechazo a lo ilustrado (propio de la razón y la racionalidad) por ser percibido como una depravación; 4) el miedo y desprecio a lo diferente: lo distinto es categorizado como un "intruso"; 5) una obsesión con un complot anti-sistema por parte de lo contrario: entendido este como "el enemigo"; 6) una vida por la lucha que busca, con un importante culto a la muerte y al heroísmo, el conflicto permanente contra "el enemigo": una actitud anti-pacifista; 7) un anhelo al uso de la fuerza para solucionar las problemáticas; 8) alabanza al machismo: desprecio hacia la mujer y a la homosexualidad; 9) la privación de la libertad de pensamiento y de expresión: el pensamiento sufre una castración a modo de "prevención"; 10) abuso del populismo; 11) elitismo y desprecio por los ciudadanos débiles; 12) el uso de la neolengua: la difusión de un léxico pobre en los sistemas educativos con el fin de evitar el razonamiento complejo del alumnado; 13) el llamamiento a las clases medias frustradas como un "público" vulnerable e influenciable; 14) rechazo hacia el libre pensamiento, entendido este como una forma de "traición".

Tal como se puede denotar de lo expuesto, cada uno de los indicadores tiene un terrible símil al tradicionalismo homérico que ahogó la razón socrática, al silenciado aporte científico de Prometeo, al bloqueado pensamiento copernicano y galileano o al conocimiento calcinado en la biblioteca de Alejandría; indicios de la perdurabilidad e inmutabilidad del supuesto de infalibilidad de las autoridades centristas que, a lo largo de la historia de la humanidad, han dominado y subyugado a las parcelas más vulnerables de la ciudadanía ${ }^{29}$.

\section{La inclusión del talante socrático en la Academia y la función humanizadora de los Estudios Generales.}

Los ejemplos hasta aquí descritos sirven para mostrar el importante papel que cumplen los sistemas educativos en general, y las Universidades en particular, para con la ciudadanía y el desarrollo sociocultural de un Estado en concreto. No obstante, a diferencia de los demás casos expuestos, la situación de Sócrates y el contexto que lo envolvía puede ser muy fructífero a la hora de afrontar las controversias educacionales actuales. Nuestra cotidianidad académica se desarrolla en un contexto sociocultural que bien puede fundamentarse, en gran medida, en el tradicionalismo y el criterio de infalibilidad de valores arraigados, especialmente religiosos y políticos; cualquier ápice de cuestionamiento hacia tales valores normativizados, y normativistas, será entendido como sinónimo de rivalidad y amenaza.

Martha Nussbaum (2005) sostiene de un modo optimista: “... nuestras facultades tratan de cumplir con la misión socrática original, cuestionando realmente a todos y reconociendo la humanidad de todos" (p. 54), y como consecuencia, "están siendo acusadas de corromper a los jóvenes y de desarmonizar el tejido sociocultural relativo al pensamiento tradicional" (p. 35-36). Por lo antes referido, nos encontramos en una rivalidad entre el tradicionalismo adueñado de lo sociocultural y el libre desarrollo intelectual que propician ciertas universidades a partir de la metodología socrática y la investigación ${ }^{30}$. Se trata, pues, de una rivalidad entre el supuesto de infalibilidad que propicia servidumbre intelectual-ceguera moral y la actitud inquisitiva que, mediante el cuestionamiento y el autoexamen que

\footnotetext{
${ }^{28}$ Del término fasces, del latín fascis (puñado, haz o manojo), y, posteriormente, del italiano fascio; asignado como el emblema y signo del poder militar de los reyes etruscos y del Imperio Romano.

${ }^{29}$ El hecho de hacer un repaso histórico no debe interpretarse como si el supuesto de infalibilidad o los rasgos que caracterizan el fascismo hubieran desaparecido, o como si la libertad de pensamiento y de expresión estuvieran exentas de peligro en la actualidad, pues determinadas formas de hacer o de perseverar la cultura en sociedades actuales, especialmente desde el plano educativo, resisten al tiempo y continúan encarcelando a la razón y a la verdad.

30 Una investigación que, para una culminante misión de desarrollo cultural, debe considerar todos los ámbitos del saber como objeto de estudio, sin excluir ninguna parcela del conocimiento, desde una óptica integral y holista del conocimiento. Como resultará lógico, no podemos entender que la investigación se centre exclusivamente en las ciencias naturales o las ciencias tecnológicas sin invitar a las humanidades, pues estaríamos capando, muy vulgarmente, el potencial de nuestra investigación, los resultados de la misma investigación y los rasgos humanistas de toda ciencia.
} 
despierta el análisis lógico y la argumentación crítica, busca nuevas veredas para entender la verdad y la justicia en el entorno sociocultural. Tal como menciona Platón: "una vida sin autoexamen no es una vida digna de vivir" (Platón, 2007, 38a), considerando que una vida debe ser susceptible al cambio para el desarrollo y la culminación. Contrariamente, una vida sin autoexamen propicia que los ciudadanos permanezcan en una forma de servidumbre intelectual y moral y "sean peligrosamente influenciables" (Nussbaum, 2010, p. 78).

Si podemos concebir el autoexamen socrático como el instrumento para el desarrollo humano de un individuo en virtud de la superación de lo convencionalmente establecido, como el poder normativista del tradicionalismo dogmatizador, podemos entender que la reflexión y la argumentación crítica son el eje vertebrador de la educación democrática, aquella educación que procura la convivencia en pro de la libertad, la igualdad y la autonomía de todos sus ciudadanos. Por lo que se desprende, podemos encajar ciertos rasgos socráticos a la educación actual, con el fin de socratizarla-democratizarla, a partir de los enunciados propuestos por Nussbaum (2005), a saber: 1) la educación es para todos los seres humanos (carácter universal); 2) la educación debe adaptarse a las circunstancias y al contexto del alumno (debe adaptarse a las particularidades humanas); 3) la educación debe ser pluralista; atenta a una diversidad de normas y tradiciones (atiende a la diversidad cultural del ser humano); 4) la educación requiere argumentar que los libros no se transformen en autoridades dogmáticas (la educación no debe encerrarse en los textos escritos).

Cuando nos encontramos ante un sistema educativo que proyecta los saberes desde una óptica cultural unidimensional y unidireccional, y que no propicia espacio para el cuestionamiento, nos encontramos ante un sistema educativo que, de un modo directo, coacciona la libertad de pensamiento y de expresión de los alumnos en particular y, de un modo indirecto, detiene el desarrollo cultural de una sociedad en general. En tinta de Michel Foucault, el poder es entendido como un medio de coacción y dominación que escapa del ámbito político y jurídico; "... creo que los mecanismos de poder son mucho más amplios que el mero aparato jurídico, legal, y que el poder se ejerce mediante procedimientos de dominación que son muy numerosos" (Foucault, 2013, p. 63). Por lo mencionado, es lógico suponer que nos encontramos ante formas de poder que, desde la esfera institucional de lo académico, se practica una producción técnica de lo individual y lo identitario en función de lo establecido normativamente; una terrorífica situación de carácter orwelliano.

Como brillante alternativa a tan peligrosa situación sociocultural y académica, los Estudios Generales (o Artes Liberales) ${ }^{31}$ plantean una mirada pedagógica que alumbra las cuestiones fundamentales de la existencia humana; una visión académica de carácter holístico, transversal y democratizador que, para contrarrestar la exagerada profesionalización de los estudios universitarios, propone el cultivo intelectual y moral del alumnado eludiendo cualquier tipo de profesionalización. El conocimiento impartido desde los Estudios Generales cumple con las premisas propuestas por Nussbaum (2005), expuestas anteriormente, en virtud de la metodología socrática y el espíritu democratizador, además de cumplir con determinados aspectos alumbrados en los apartados anteriores, tales como: 1) la inicial humildad intelectual del docente y del alumno; 2) la importancia del método dialógico y mayéutico en la metodología pedagógica; 3) examinar lo establecido mediante el análisis lógico; 4) el incentivo de buscar la veracidad desde el cuestionamiento y la argumentación crítica; 5) la reanimación y/o reforzamiento del carácter investigativo de laAcademia; 6) hacer florecer personas y ciudadanos libres mediante el cultivo de su autonomía intelectual y moral.

Los cimientos de la democracia (la igualdad, la libertad y la autonomía del ciudadano) no solamente deben estar presentes en los contenidos a impartir o en el eslogan de la institución académica, sino en el modo de seleccionar e impartir tales contenidos y el ejemplo conductual que exhibe la misma institución. Resultaría paradójico impartir contenidos de historia o filosofía relativos a la libertad de pensamiento y expresión, desde una institución que defiende tal principio, si no se imparte ofreciendo al alumnado la libertad de pensamiento y expresión. Otro ejemplo puede basarse en tantas instituciones que brindan alabanza a la paridad de género cuando educan "para" la igualdad desde conductas discriminatorias, en lugar de educar "desde" la igualdad con conductas inclusivas. La coherencia en la enseñanza, por ende, resulta vital

\footnotetext{
${ }^{31}$ El concepto de Estudios Generales, heredado del Trivium (gramática, dialéctica y retórica) y el Quadrivium (aritmética, geometría, astronomía y música) de las Universidades medievales, enfoca la educación universitaria con unos conocimientos democratizadores y humanizadores. La educación impartida desde los Estudios Generales comprende el conocimiento desde una óptica holística; la enseñanza no responde a ninguna especialización o vocación profesional, sino al cultivo de la persona como un ser autónomo-libre y a la ampliación de los horizontes intelectuales, morales y culturales del alumnado-ciudadanía. En este sentido, la transversalidad del conocimiento es una de las características clave a la hora de entender la esencia de los Estudios Generales.
} 
para que el ejemplo que se manifiesta desde las instituciones académicas promuevan, incentiven y provoquen un impacto en el alumnado y en el mismo cuerpo profesoral, de un modo directo, y un impacto en la sociedad y cultura, de un modo indirecto. En este orden de ideas, podemos determinar que las características de la maestría socrática, análogamente al concepto de Estudios Generales, impulsan al alumnado a reflexionar y expresarse libremente, a analizar lógicamente y a argumentar críticamente sobre el entorno sociocultural y político que lo envuelve; a conocerse intelectual y moralmente, a valerse libre y autónomamente y a convivir con uno mismo desde el equilibrio espiritual ${ }^{32}$.

Aquellas doctrinas consideradas como infalibles e irrefutables deben ser objeto de estudio a partir del examen ciudadano; una posibilidad que, de un modo exclusivo, puede auspiciarse desde una educación democratizadora y humanizadora (o "socratizada") como los Estudios Generales. De este modo, debemos ser conscientes del papel que cumple el discurso filosófico en el ámbito académico, pues el cuestionamiento y la reflexión deben dejar de ser percibidas como quimeras o actitudes "extrañas"; pues la importancia de reflexionar sobre lo que ya damos por sabido es vital para que el desarrollo intelectual y moral de la ciudadanía no permanezca estancado en las arenas. Solamente cuando el alumnado-ciudadanía sea capaz de reflexionar por sí mismo y se involucre en los asuntos públicos y políticos de una manera autónoma y responsable, después de percatarse del protagonismo que él mismo merece y tiene en el ámbito social, podremos hablar de una democracia sin mediocres "escaparatismos" y de una revolución educativa sin vulgares pantomimas.

\section{Referencias}

Álvarez, D. (1994) Sócrates: Maestro y filósofo. Aula $2000(35)$

Aristófanes (2012) Nubes. Buenos Aires: Editorial Losada.

Aristóteles (2001) Tratados de lógica: El organon. México: Editorial Porrua

Brun, J. (2005) Sócrates. Barcelona: Edicions de 1984.

Eco, U. (1995) The Ney York Review of Books: UrFascism. New Yotk, EU. Recuperado de: http://www. nybooks.com/articles/1995/06/22/ur-fascism/
Farrington, B. (1973) Ciencia y política en el mundo antiguo. Madrid: Editorial Ayuso.

Foucault, M. (2013) El poder, una bestia magnífica. México: Siglo XXI Editores.

Gadotti, M. (2003) Historia de las ideas pedagógicas. México: Siglo XXI Editores.

Homero (2016) Odisea. Madrid: Alianza Editorial.

Jaeger, W. (1996) Paideia: los ideales de la cultura griega. México: Fondo de cultura económica.

Jenofonte (1967) Recuerdos de Sócrates. Apología. Simposio. Madrid: Alianza Editorial.

Marrou, H. (2004) Historia de la educación en la Antigüedad. Madrid: Akal.

Nussbaum, M. (2005) El cultivo de la humanidad. Una defensa clásica de la reforma en la educación liberal. Barcelona: Paidós Básica.

Nussbaum, M. (2010) Sin fines de lucro. Por qué la democracia necesita de las humanidades. Madrid: Katz Editores.

Platón (1988) Fedón. Banquete. Fedro. Madrid: Gredos.

Platón (2005) Parménides. Madrid: Alianza Editorial.

Platón (2007) Apología de Sócrates. Menón. Crátilo. Madrid: Alianza Editorial.

Platón (2013) La República. Madrid: Alianza Editorial.

Steiner, G. (2003) Lecciones de los maestros. Madrid: Siruela.

Stuart Mill, J. (2013) Sobre la libertad. Madrid: Alianza Editorial.

Taylor, A. E. (2017) El pensamiento de Sócrates. México: Fondo de Cultura Económica.

Tovar, A. (1986) Vida de Sócrates. Madrid: Alianza Editorial.

Wolff, J. (2012) Filosofía Política. Una introducción. Barcelona: Editorial Ariel.

\footnotetext{
32 Requisitos indispensables para saber convivir con el resto, comportarnos como ciudadanos democráticos y generar un tejido sociocultural lo suficientemente resistente como para avanzar al unísono.
} 